\title{
REFLEXÕES SOBRE O METABOLISMO BIOSSINTÉTICO DAS PIRETRINAS I E II - REVISÃO E SUGESTÕES
}

LUIZ ERLON A. RODRIGUES *

Esta revisão de literatura sobre o metabolismo biossintético das piretrinas I e II sugere várias etapas intermediárias desses processos metabólicos com o intuito de facilitar o entendimento dos inúmeros obstáculos bioquímicos ainda por serem elucidados e compreendidos. Apesar do grande desenvolvimento industrial na fabricação de derivados sintéticos das piretrinas, a exemplo dos piretroides, a alta demanda e importância comercial desses inseticidas continuam a estimular sua biossíntese por intermédio da biotecnologia, do uso de biorreatores, da bioconversão de precursores por enzimas isoladas de folhas e flores dos crisântemos ou, ainda, por micro-organismos geneticamente modificados.

PALAVRAS-CHAVE: PIRETROIDES; INSETICIDAS; ÁCIDO CRISANTÊMICO; ISOPRENOIDES.

* Professor Titular, Doutor em Bioquímica, EBMSP - Fundação Bahiana para o Desenvolvimento das Ciências, Salvador, Bahia, Brasil (e-mail: erlon@svn.com.br). 


\section{INTRODUÇÃO}

O pó ou extratos feitos a partir das folhas de várias espécies de crisântemos ou píretros como, por exemplo, o Chrysanthemum cinerariaefolium têm sido usados há mais de dois séculos como inseticidas e no controle de pestes.

No início do século XIX, flores do píretro (Chrysanthemum coccineum) foram utilizadas no controle de piolhos por tribos Caucasianas e Persas (JOVETIC, 1994). Antes da segunda guerra mundial, os extratos de píretro foram muito importantes para o controle de insetos caseiros, limpeza de celeiros e estábulos, assim como para a conservação de produtos agrícolas estocados. Foram substituídos por praguicidas sintéticos, mais estáveis, porém mais tóxicos para o meio ambiente como os organoclorados, os metilcarbamatos e os organofosforados. O píretro se destaca por agir rapidamente contra vários tipos de insetos, além de causar pequenos danos ao meio ambiente e ser menos tóxico para mamíferos e outros animais.

As piretrinas, substâncias ativas contidas nos extratos do píretro, foram identificadas no início do século XX e isoladas como ésteres dos ácidos crisantêmico e pirétrico para as piretrinas dos tipos I e II, respectivamente. As metades alcoólicas desses ésteres são representadas por três ciclopentenolonas, a piretrolona, a jasmolona e a cinerolona.

De acordo com Wanyika et al. (2009), apesar da introdução dos inseticidas sintéticos, o uso do píretro continua crescente, principalmente pela vantagem de ser muito menos tóxico para mamíferos e causar poucos danos ao meio ambiente. Contudo, as piretrinas não são foto estáveis e perdem, rapidamente, sua eficácia como inseticida quando em soluções.

A foto instabilidade é atribuída à mudança para o isômero trans (E) da dupla ligação cis (Z) contida na cadeia lateral dos ácidos crisantêmico e pirétrico. Os isômeros trans são praticamente inativos. Além disso, as piretrinas são moléculas que continuadamente mudam de conformação estrutural no espaço devido aos seus centros quirais e a temperatura do ambiente. Pequenas alterações constitucionais ou configuracionais em qualquer parte de suas moléculas podem exercer grande influência em sua atividade como inseticida. Várias substâncias têm sido adicionadas às soluções das piretrinas com a finalidade de diminuir sua instabilidade e conservar sua eficácia. Dentre elas, destacam-se os antioxidantes e estabilizadores, a exemplo do ácido tânico e da hidroquinona, triglicerídios derivados de óleos vegetais, o óleo de neem e o de algodão (WANYIKA et al., 2009). O grau de estabilidade alcançado por alguns piretroides mais modernos, obtidos por síntese, tem estimulado o aparecimento de resistência nos insetos, aumentado o potencial de toxicidade e desencadeado efeitos carcinogênicos em mamíferos. Tais fatos contribuíram para o retorno das atenções para as piretrinas naturais (JOVETIC, 1994).

A importância comercial, assim como a alta demanda, além das dificuldades no suprimento do píretro continuam estimulando as pesquisas para a obtenção de piretróides de terceira e quarta gerações (GLYNNE-JONES, 2001).

Propõe-se nesta revisão uma abordagem detalhada das diversas etapas metabólicas que caracterizam a biossíntese das piretrinas com o intuito de facilitar o entendimento dos inúmeros obstáculos inerentes ao desenvolvimento em escala industrial com o uso de biorreatores, da bioconversão de precursores por enzimas isoladas ou de microorganismos geneticamente modificados.

\section{COMPOSIÇÃO QUÍMICA DOS EXTRATOS DO PÍRETRO}

A Figura 1 mostra as piretrinas I e II, as jasmolinas I e II e as cinerinas I e II, os seis principais ésteres que constituem os extratos do píretro. Os componentes do tipo I são ésteres do ácido crisantêmico e os do tipo II do ácido pirétrico. 


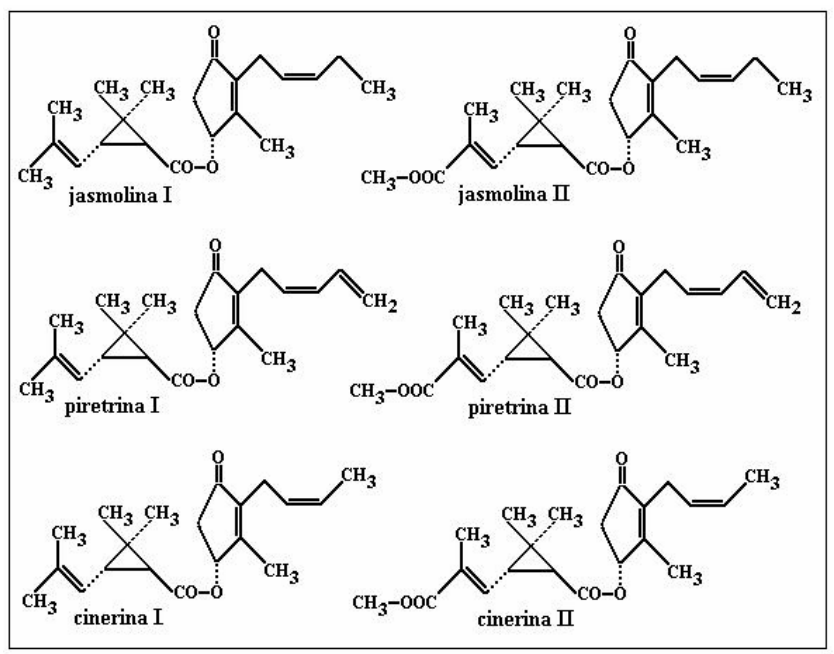

\section{FIGURA 1 - FÓRMULAS ESTRUTURAIS DAS JASMOLINAS I E II, DAS PIRETRINAS I E II, e CINERINAS I E II}

De acordo com GLYNNE-JONES (2001), as concentrações dos produtos dependem do tipo de planta, das condições dos terrenos de cultivo, do tempo da colheita e dos solventes utilizados nas extrações. Em termos médios, as proporções relativas das piretrinas presentes num extrato concentrado a $50 \%$ são de $19 \%$ para a piretrina I, 3,7\% para a cinerina I, 2,0\% de jasmolina I, $17,5 \%$ de piretrina II, $5,8 \%$ de cinerina II e $2,0 \%$ de jasmolina II.

\section{BIOSSÍNTESE DO ÁCIDO CRISANTÊMICO}

Mais de 50.000 diferentes tipos de moléculas derivadas dos isoprenoides (terpenos e terpenoides) desempenham funções muito importantes no metabolismo de todos os tipos de células, em todas as formas de vida.

O crisantemoil-difosfato, precursor alcoólico ativado do ácido crisantêmico, é sintetizado por plantas da família Compositae incluindo os gêneros Chrysanthemum, Tagetes, Artemísia e Santolina. Ele resulta das reações de alongamento e ciclopropanação entre moléculas de dimetilalil-difosfato e de isopentenil-difosfato, catalisadas pela enzima crisantemoil-difosfato sintetase (ERICKSON e POULTER, 2003). A Figura 2 descreve essas reações.

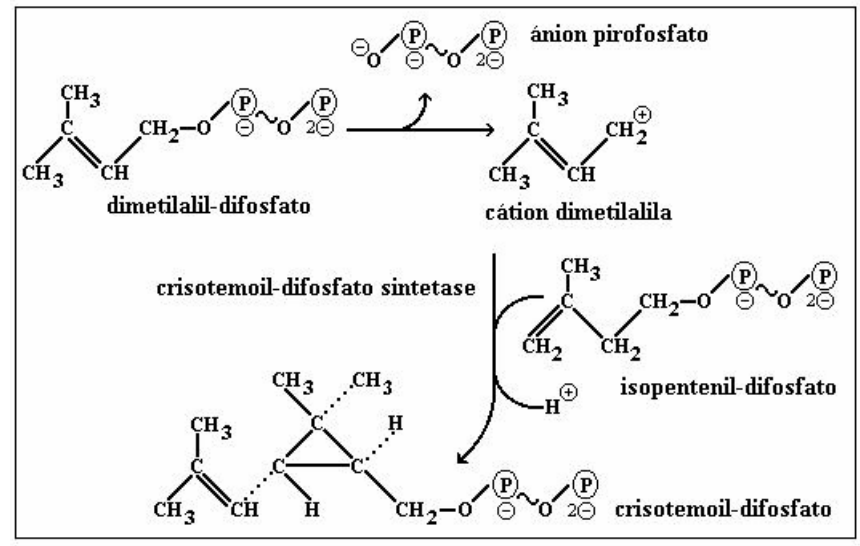

FIGURA 2 - SINOPSE DA BIOSSÍNTESE DO CRISANTEMOIL-DIFOSFATO 
A elongação da cadeia inicia-se com a dissociação do cátion dimetilalila e do ânion pirofosfato inorgânico, seguida da alquilação eletrofílica da dupla ligação do isopentenil-difosfato. A energia necessária para esse alongamento e ciclopropanação é, em parte, fornecida pela hidrólise da ligação anídrica do pirofosfato, catalisada por uma pirofosfato hidrolase o que torna as reações irreversíveis, favorecendo a síntese do crisantemoil-difosfato.

O crisantemol resulta da desativação do crisantemoil-difosfato sob a ação de uma fosfohidrolase. O crisantemol, por sua vez, pode ser oxidado a ácido crisantêmico pelas oxidorredutases de baixa especificidade a álcool desidrogenase e a aldeído desidrogenase. Essas transformações são mostradas na Figura 3.

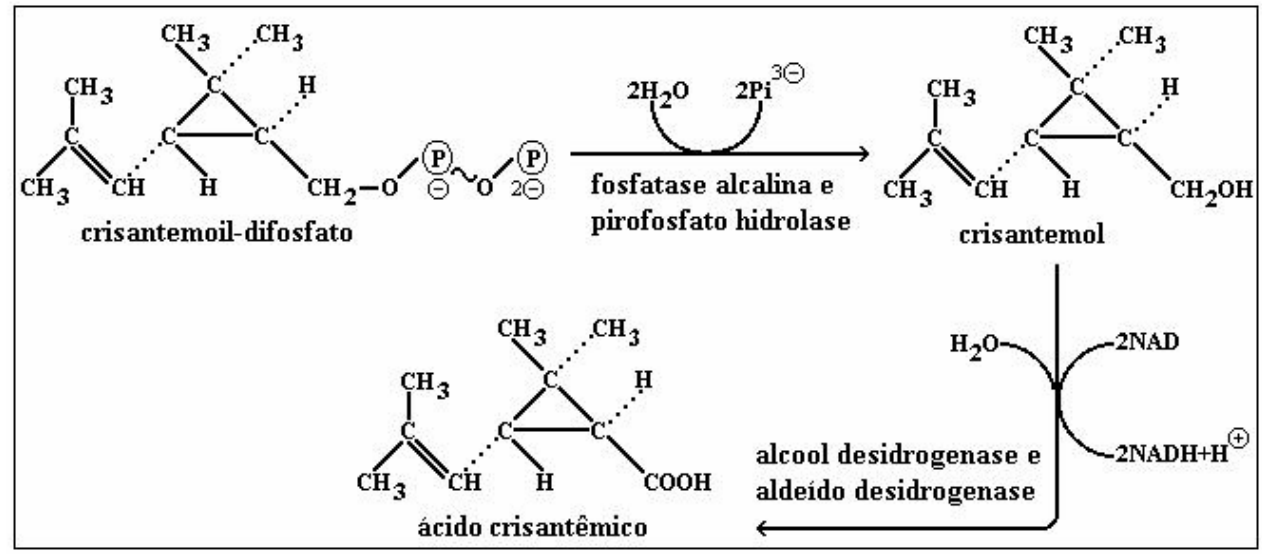

\section{FIGURA 3 - OBTENÇÃO DO ÁCIDO CRISANTÊMICO A PARTIR DO CRISANTEMOIL-DIFOSFATO}

Segundo Lichtenthaler (1999), a biossíntese do isopentenil-difosfato, usado no metabolismo dos isoprenoides, carotenoides, fitois, esterois, plastoquinonas, monoterpenos, diterpenos e politerpenos está ligada ao metabolismo do acetato/mevalonato. Até a década de oitenta essa era a única via de biossíntese conhecida para o mevalonato nos animais, fungos e bactérias. Contudo, de acordo com Chappell et al. (1995), vários estudos demonstraram que a utilização da mevinolina ou da compactina, isoladas dos fungos Aspergillus terreus e Monascus ruber e potentes inibidores da 3-hidroxi-3-metilglutaril-CoA redutase, eram capazes de inibir fortemente a biossíntese de esterois citossólicos e da ubiquinona. Enquanto isso, os plastídios continuavam a sintetizar o fitol, carotenoides e plastoquinona-9. Em 1999, McCaskill e Croteau usaram ${ }^{14} \mathrm{C}$-piruvato para demonstrar, que eubactérias e plantas superiores sintetizavam monoterpenos, diterpenos e tetraterpenos mediante via metabólica não dependente do mevalonato, conhecida como via da 1desoxi-D-xilulose-5-fosfato.

\section{BIOSSÍNTESE DO ISOPENTENIL-DIFOSFATO VIA MEVALONATO}

Os isoprenoides são sintetizados em pelo menos três compartimentos subcelulares nas plantas superiores. No citoplasma são sintetizados os esterois, os plastídios, responsáveis pela síntese das clorofilas, carotenoides e prenilquinonas e nas mitocôndrias é sintetizada a ubiquinona.

A via citoplasmática ou via do acetato/mevalonato inicia-se com a formação do 3-cetobutiril-CoA a partir de duas moléculas de acetil-CoA catalisadas pela enzima acetil-CoA acetil transferase (Figura 4). 


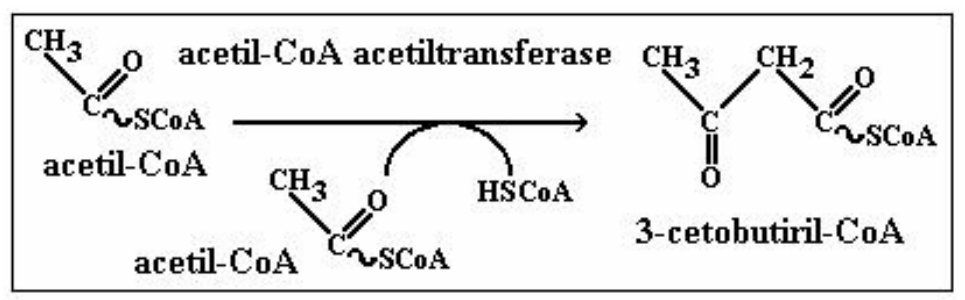

\section{FIGURA 4 - BIOSSÍNTESE DO 3-CETOBUTIRIL-COA A PARTIR DE DUAS MOLÉCULAS DE ACETIL-CoA}

Segundo D'Auria (2006), a ativação de grupos acilas dentre eles o acetila pela CoA (coenzima A) e transferência para vários receptores contribui, nas plantas, para a biossíntese de muitos terpenos, alcaloides, reguladores do crescimento (giberelinas, ácido abscísico e citocininas), fitoalexinas, antocianidinas, ácidos graxos e açúcares acetilados essenciais para o crescimento normal, o desenvolvimento e a defesa contra agentes patogênicos.

O 3-cetobutiril-CoA adiciona mais um acetil-CoA numa reação de redução do grupo carbonila secundário para álcool terciário, catalisada pela enzima 3-hidroxi-3-metilglutaril-CoA sintetase. Essa reação está expressa na Figura 5.

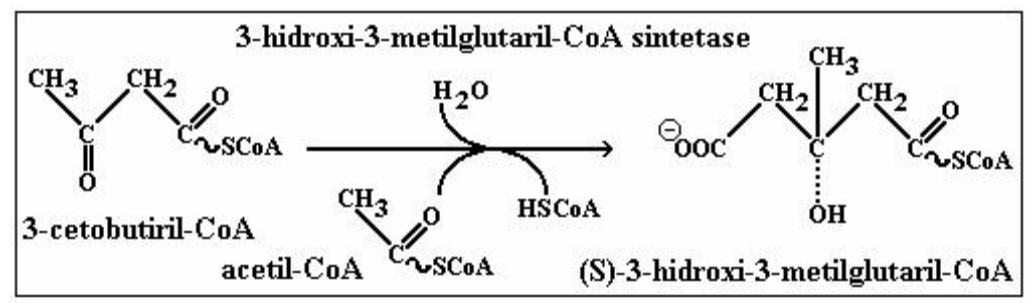

\section{FIGURA 5 - ADIÇÃO REDUTORA DE UM ACETIL-CoA PELO 3-CETOBUTIRIL-CoA}

Alex, Bach e Chye (2000) isolaram o gene que expressa a 3-hidroxi-3-metilglutaril-CoA sintetase a partir de Brassica juncea (presente em todos os órgãos da planta mostarda indiana). Essa enzima está relacionada ao desenvolvimento e regulação da floração, formação das sementes e crescimento das mudas, sendo inibida alostericamente pelo ácido abscísico, estresse osmótico e desidratação. A cicatrização, o metiljasmonato e o ácido salicílico induzem a expressão da enzima sugerindo sua ligação com os mecanismos de defesa das plantas aos agentes agressores.

Como mostra a Figura 6, o 3-hidroxi-3-metilglutaril-CoA vai ser, em seguida, reduzido para ácido mevalônico (mevalonato) pela enzima 3-hidroxi-3-metilglutaril-CoA redutase (HMG-CoA redutase), dependente de duas moléculas de NADP (fosfato do nicotinamida adenina dinucleotídio) reduzidos. A redução do grupo acil-CoA envolve a liberação da CoA e a energia resultante é utilizada na formação do aldeído meváldico, composto intermediário, que por sua vez é reduzido para o álcool primário, o ácido mevalônico.

A HMG-CoA redutase é uma enzima chave no controle metabólico de importantes funções vegetais. Níveis maiores de atividade são comumente associados ao rápido crescimento de partes das plantas, a exemplo de brotos apicais, botões florais e raízes. Segundo Stermer, Bianchini e Korth (1994), no tomate, a atividade dessa redutase é mais alta nas fases precoces do desenvolvimento do fruto, quando se observa o estímulo da divisão celular. O incremento da atividade está intimamente ligado ao aumento dos teores de pigmentos carotenoides que acompanham o amadurecimento dos frutos. Sua atividade enzimática é regulada, em parte, pelos níveis do seu mRNA, (RNA mensageiro), assim como por reversível fosforilação de hidroxilas serínicas presentes em seus centros ativos. De 
acordo com Rodrigues (2006) essa enzima existe sob duas formas, uma mais ativa, não fosforilada e outra menos ativa que resulta da fosforilação das hidroxilas serínicas dos seus centros ativos pela enzima redutase cinase (ATP: hidroximetilglutaril-CoA redutase fosfotransferase). O retorno à forma mais ativa ocorre mediante desfosforilação por fosfatase específica, a hidroximetilglutaril-CoA redutase fosfatase (hidroximetilglutaril-CoA fosfohidrolase). A Figura 7 resume as etapas de ativação/desativação.

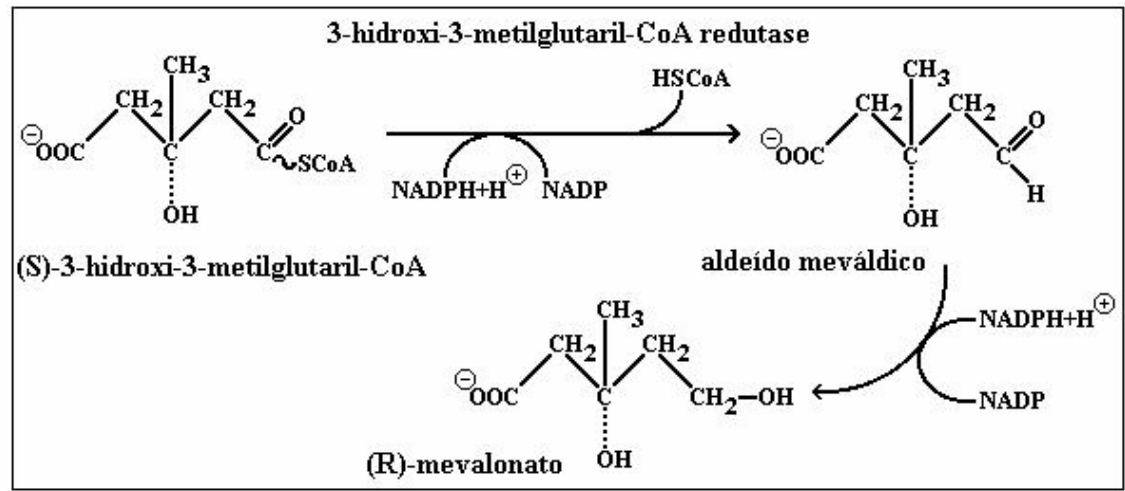

FIGURA 6 - ETAPAS CATALISADAS PELA 3-HIDROXI-3-METILGLUTARIL-CoA REDUTASE

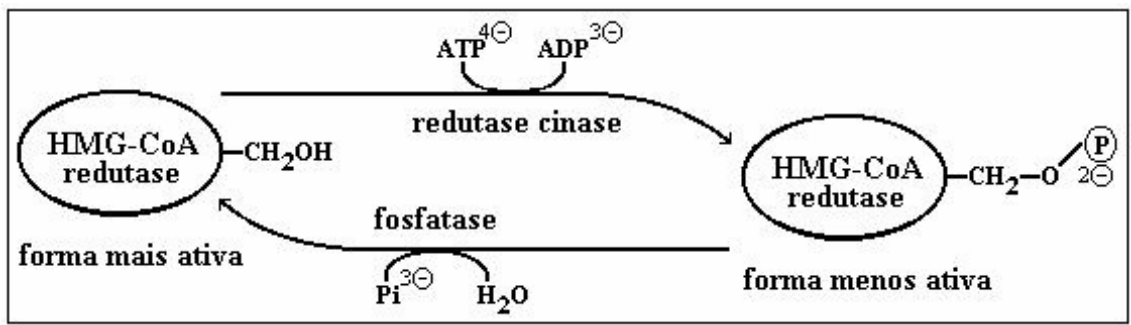

\section{FIGURA 7 - TIPOS FISIOLÓGICOS DA HMG-CoA REDUTASE}

A conversão do mevalonato em unidades isoprenoides simples, a exemplo do isopentenildifosfato e do dimetilalil-difosfato, é catalisada por enzimas solúveis no citoplasma e envolve gasto de ATP (adenosina trifosfato). Como está expresso na Figura 8, a mevalonato cinase I (ATP: (R)-mevalonato5-fosfotransferase) fosforila uma vez o carbono alcoólico primário do mevalonato transformando-o em 5-fosfo-mevalonato. Outros nucleotídios trifosforilados, a exemplo do UTP (uridina trifosfato), CTP (citidina trifosfato) e GTP (guanosina trifosfato) podem funcionar como doadores de fosfato. Logo em seguida, como mostrado na Figura 9, a mevalonato cinase II (fosfomevalonato cinase) fosforila mais uma vez 0 (R)-mevalonato-5-fosfato transformando-o em (R)-mevalonato-5-difosfato, conservando parte da energia disponível do ATP numa ligação pirofosfórica anídrica, rica em energia.

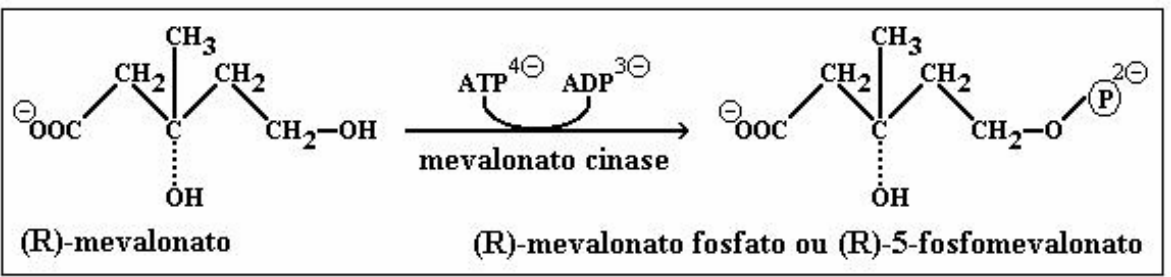

FIGURA 8 - PRIMEIRA ATIVAÇÃO DO MEVALONATO 


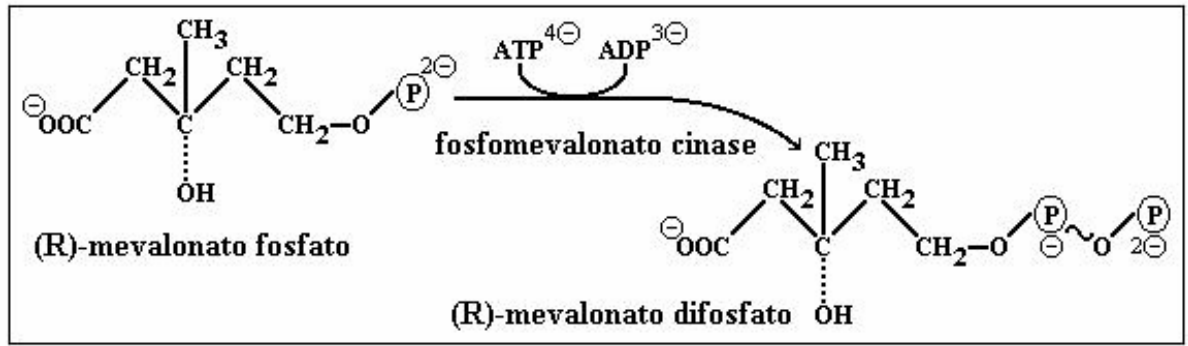

\section{FIGURA 9 - SEGUNDA ATIVAÇÃO DO MEVALONATO}

A mevalonato difosfato descarboxilase transforma o (R)-mevalonato-5-difosfato em isopentenildifosfato após descarboxilação e consequente desidratação. Essa descarboxilação é francamente endergônica e, portanto, necessita de fonte energética disponível. O mol da água liberada na desidratação do álcool terciário hidrolisa um mol de ATP para ADP (adenosina difosfato) e fosfato inorgânico, fornecendo a energia necessária para a citada descarboxilação (Figura 10).

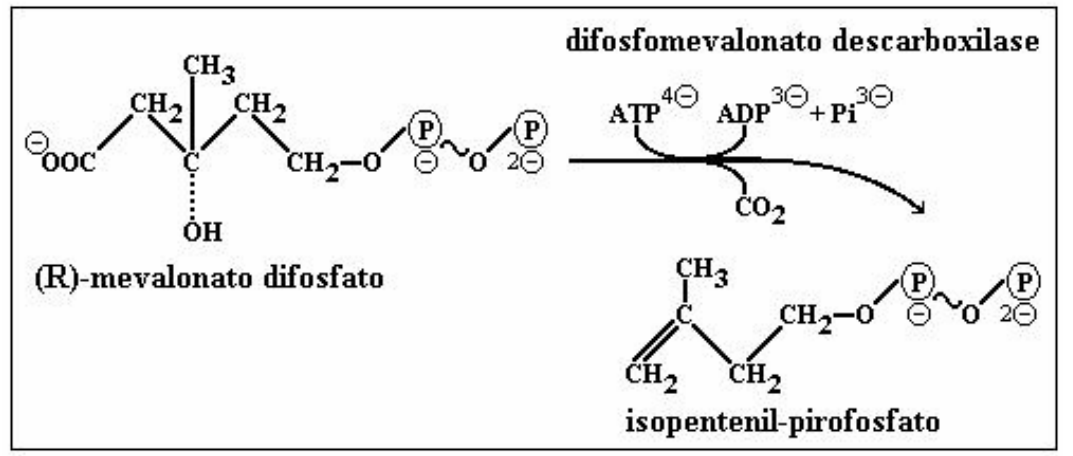

\section{FIGURA 10 - OBTENÇÃO DO ISOPENTENIL-DIFOSFATO A PARTIR DO MEVALONATO-DIFOSFATO}

\section{BIOSSÍNTESE DO ISOPENTENIL-DIFOSFATO VIA 1-DESOXI-D-XILULOSE-5-FOSFATO}

Muitas bactérias, protozoários do phylum Apicomplexa, a exemplo do Plasmodium falciparum e os plastídios das células vegetais sintetizam isoprenoides por metabolismo alternativo conhecido com via da 1-desoxi-D-xilulose-5-fosfato ou metabolismo de Rohmer (ROHMER et al., 1993). São utilizados como metabólitos iniciais o piruvato e o D-gliceroaldeído-3-fosfato, ambos produtos da via glicolítica de Embden-Meyerhof. Inicialmente, o piruvato é descarboxilado pela piruvato descarboxilase dependente de vitamina B1 ativada (tiamina difosfato, DPT), formando complexo estável entre a coenzima e o produto da descarboxilação, o complexo etanoil-tiamina difosfato-enzima.

A 1-desoxi-D-xilulose-5-fosfato sintetase (DOXP sintetase) libera o acetaldeído do complexo enzima-coenzima-produto anterior e o condensa com o D-gliceroaldeído-3-fosfato resultando na consequente recuperação da piruvato descarboxilase. Essa reação de condensação é semelhante à ação da transcetolase presente no metabolismo das pentoses. O conjunto de reações está expresso na Figura 11. 


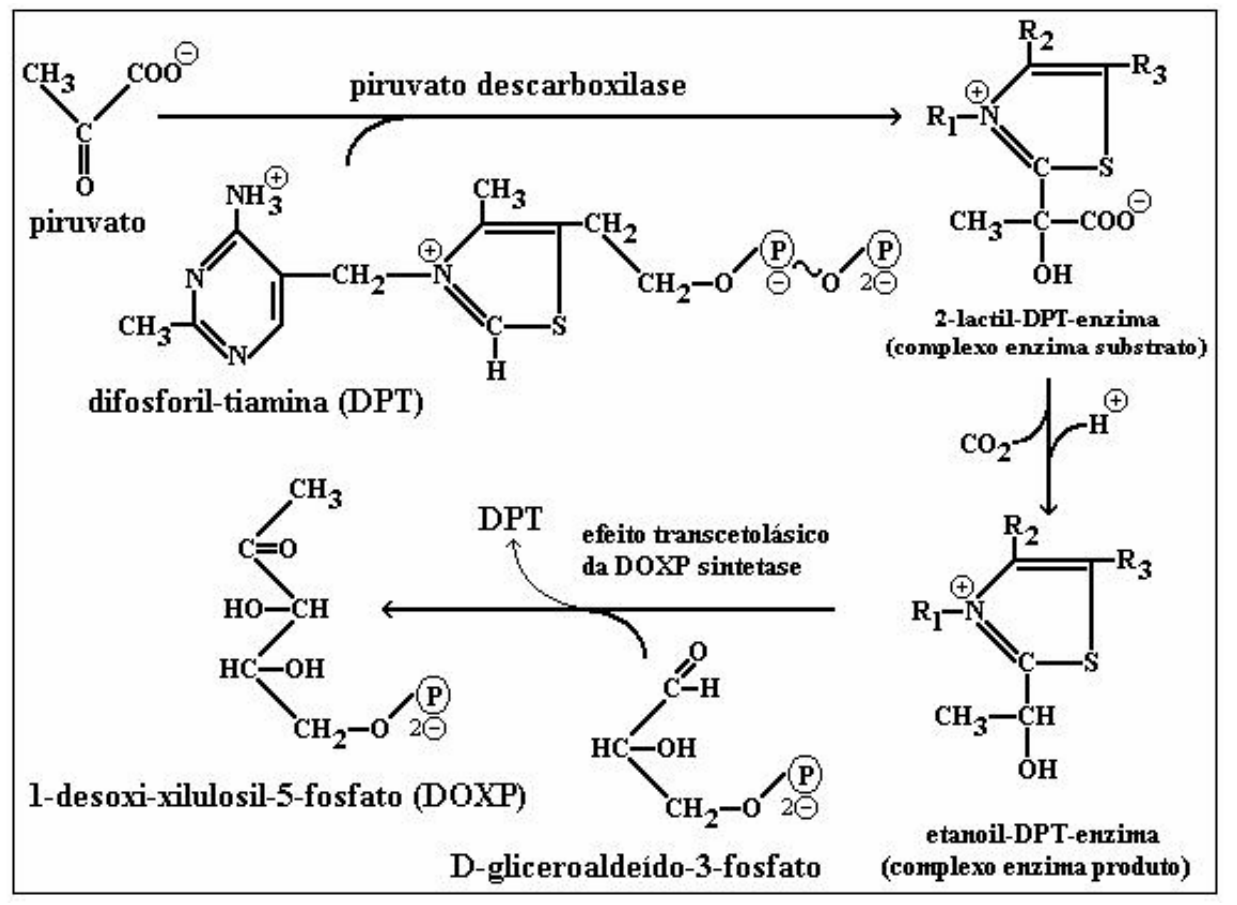

FIGURA 11 - BIOSSÍNTESE DA 1-DESOXI-D-XILULOSIL-5-FOSFATO (DOXP)

Segundo Eisenreich et al. (1998) diferentes grupos de pesquisa confirmaram a incorporação da 1-desoxi-D-xilulose-5-fosfato marcada com ${ }^{14} \mathrm{C}$ na biossíntese dos carotenos, do fitol componente da clorofila, da mentona e da ubiquinona em cultura de células de vários tipos de plantas. Subsequentemente a enzima DOXP redutoisomerase catalisa um rearranjo intramolecular da 1-desoxiD-xilulose-5-fosfato na dependência de NADP reduzido, como agente redutor, resultando no 2-C-metilD-eritritol-4-fosfato. Essa reação depende de cátions divalentes, principalmente de manganês $\left(\mathrm{Mn}^{2+}\right)$ e está resumida na Figura 12 (REUTER et al., 2002).

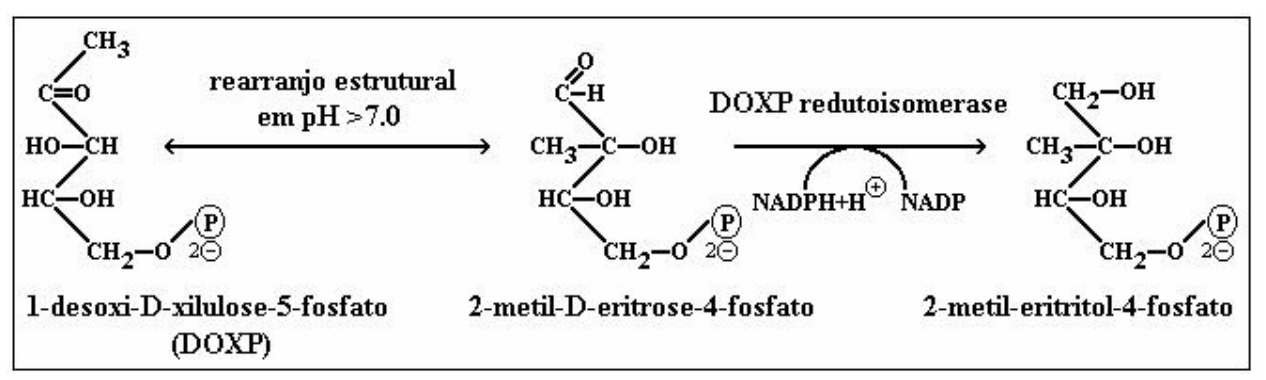

\section{FIGURA 12 - REARRANJO ESTRUTURAL DA DOXP CATALISADA PELA DOXP REDUTOISOMERASE}

A DOXP redutoisomerase tem despertado grande interesse na biologia e na medicina por causa da substância fosmidomicina, potente inibidor de sua atividade enzimática. Esse inibidor, mostrado na Figura 13, foi utilizado na cura de ratos infectados pelos Plasmodium vinckei e Plasmodium falciparum, tanto por via intraperitonial como por via oral (MISSINOU et al., 2002). Além disso, essa substância atua como inibidor competitivo com o substrato da DOXP redutoisomerase com propriedades antibacterianas e herbicidas. 


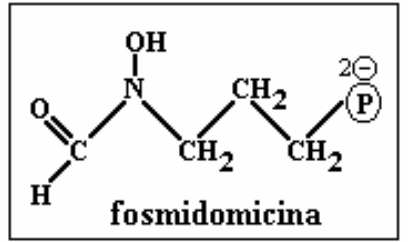

\section{FIGURA 13 - ESTRUTURA ESPACIAL SIMPLIFICADA DA FOSMIDOMICINA}

O 2-C-metil-D-eritritol-4-fosfato resultante é um composto estável e necessita de ativação prévia na sua transformação para isopentenil-difosfato. Essa ativação, expressa na Figura 14, é catalisada pela enzima 2-C-metil-D-eritritol-4-fosfato citidiltransferase, dependente de CTP (citidina trifosfato) (BOUVIER, RAHIER e CAMARA, 2005).

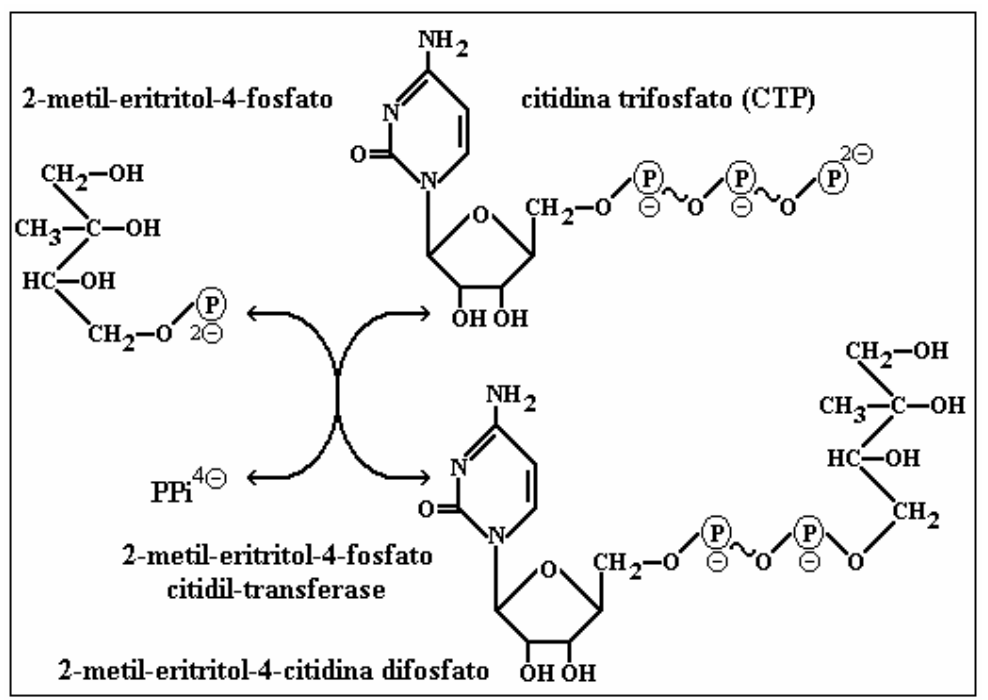

FIGURA 14 - ATIVAÇÃO DO 2-METIL-ERITRITOL-4-FOSFATO

A reversibilidade da reação pode ser anulada pela hidrólise do pirofosfato inorgânico resultante, em dois moles de fosfato, pela pirofosfato hidrolase. Com isso o segundo membro da reação torna-se menos energético que o primeiro e, portanto, o equilíbrio se desloca para a formação do produto. Subsequentemente, como mostra a Figura 15, o 2-metil-eritritol-4-citidina difosfato é fosforilado no carbono 2 pela 2-metil-eritritol-4-CDP cinase, dependente de ATP e magnésio $\left(\mathrm{Mg}^{2+}\right)$. Essa fosforilação ocorre, preferencialmente, na hidroxila ligada ao carbono terciário porque o éster resultante é mais estável (WITHERS e KEASLING, 2007).

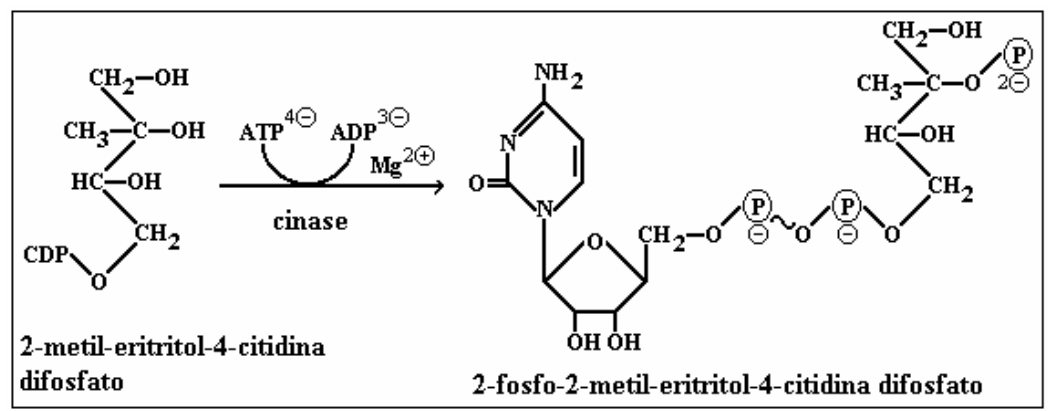

FIGURA 15 - FOSFORILAÇÃO DO 2-METIL-ERITRITOL-4-CITIDINA DIFOSFATO 
Todas as etapas precedentes convergem para a formação do 2-metil-eritritol-2,4-ciclodifosfato, composto chave na biossíntese do isopentenil-difosfato pela via alternativa de Rohmer. A2-metil-eritritol2,4-ciclodifosfato sintetase é a enzima diretamente envolvida nessa biossíntese e sua ação está expressa na Figura 16.

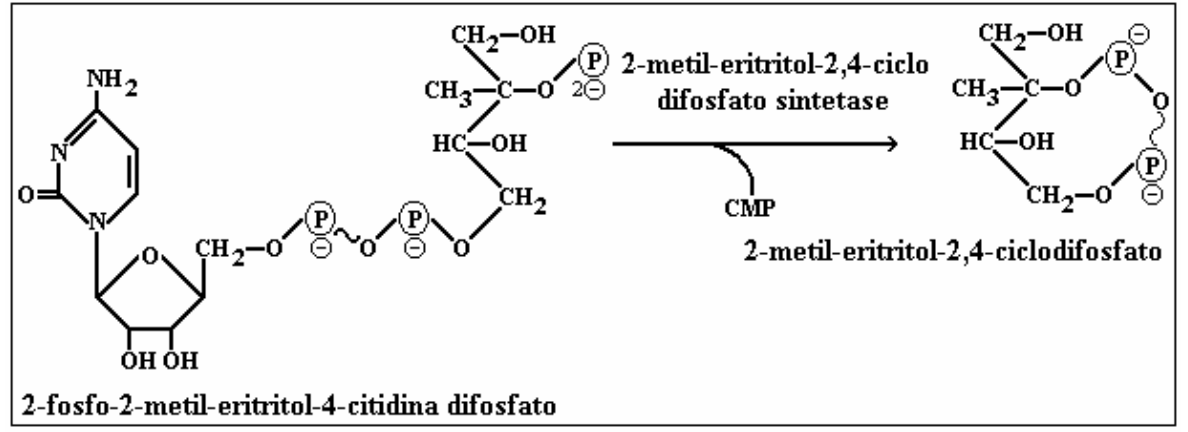

\section{FIGURA 16 - BIOSSÍNTESE DO 2-METIL-ERITRITOL-2,4-CICLODIFOSFATO}

Como o produto é um diéster cíclico instável por apresentar uma ligação anídrica pirofosfórica, rica em energia, ele é imediatamente transformado em 1-hidroxi-2-metil-2-E-butenil-4-difosfato pela sintetase correspondente, como mostra a Figura 17. Apesar da maioria dos pesquisadores considerar essa enzima como pertencente ao grupo das sintases (sintetases) ela é muito mais uma redutase dependente de NADP reduzido e que ao mesmo tempo desidrata o produto. Finalmente, esse produto é novamente reduzido e desidratado pela 1-hidroxi-2-E-butenil-4-difosfato redutase em isopentenil-difosfato como exprime a Figura 18. Essa última enzima depende, também, de NADP reduzido (KIM et al., 2008).

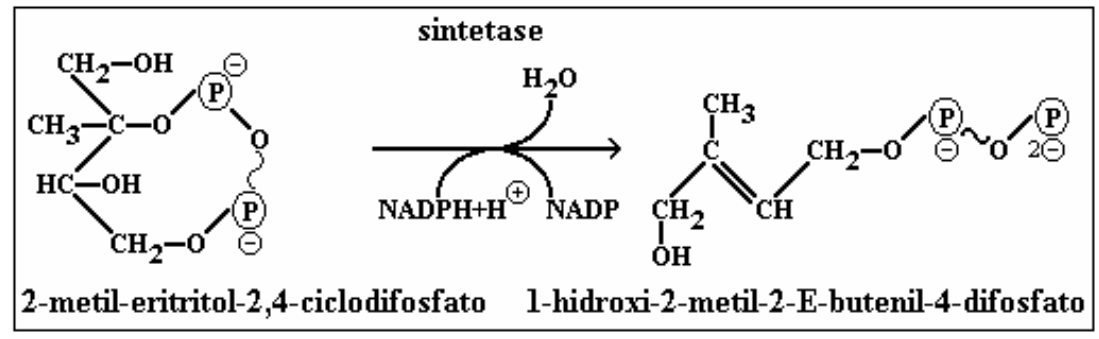

FIGURA 17 - TRANSFORMAÇÃO DO 2-METIL-ERITRITOL-2,4-CICLODIFOSFATO EM 1-HIDROXI-2-METIL-2-E-BUTENIL-4-DIFOSFATO

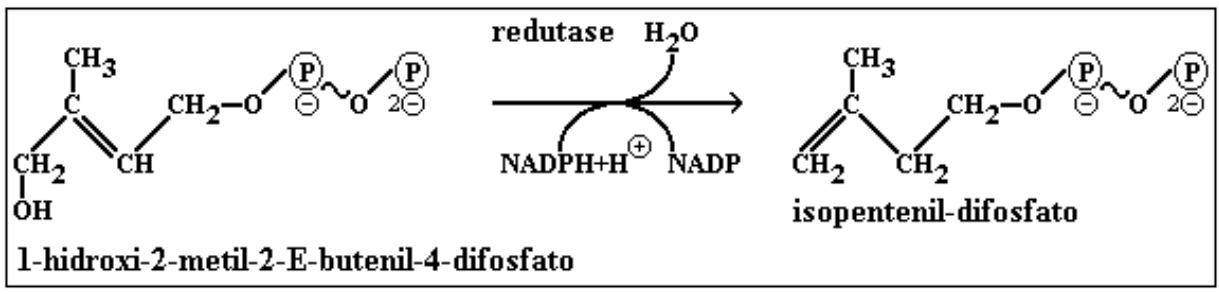

FIGURA 18 - BIOSSÍNTESE SIMPLIFICADA DO ISOPENTENIL-DIFOSFATO

\section{BIOSSÍNTESE DAS CICLOPENTENOLONAS OU RETROLONAS}

A segunda metade das piretrinas I e II é constituída por uma das retrolonas, a jasmolona, a piretrolona e a cinerolona, todas consideradas como derivadas do ácido jasmônico, importante metabólito 
amplamente distribuído por todo o reino vegetal. Segundo Mueller (1997), sua presença nas plantas pode alcançar a concentração de 3 ìg por grama de tecido fresco. Esse ácido e seus derivados estão envolvidos com a produção do pólen, com o desenvolvimento e amadurecimento dos frutos, crescimento das raízes e, principalmente, com a cicatrização e resistência dos vegetais ao ataque de agentes patogênicos.

A Figura 19 mostra as configurações moleculares decorrentes dos dois centros quirais representados pelos carbonos $\mathrm{C}_{3}$ e $\mathrm{C}_{7}$ e, portanto, responsáveis pela formação de quatro estereoisômeros possíveis. Existe a possibilidade de isomeria cis e trans envolvendo suas duas cadeias laterais. Contudo, a estabilidade dos isômeros cis é muito pequena. Os enantiômeros (3R-7R) e (3S-7S) têm suas cadeias laterais em posição trans, portanto, mais estáveis.

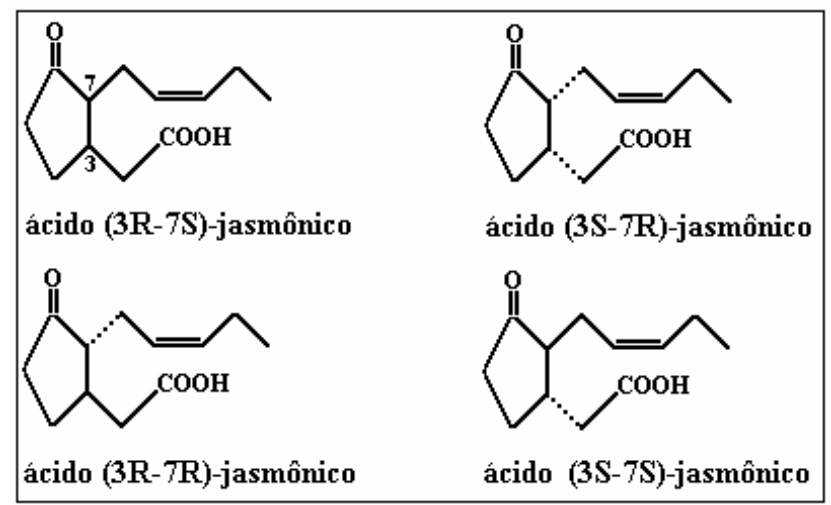

FIGURA 19 - ESTEREOISÔMEROS DO ÁCIDO JASMÔNICO

A Figura 20 mostra que os isômeros cis se epimerizam para a configuração trans mediante tautomerização ceto-enólica, envolvendo os carbonos 6 e 7.

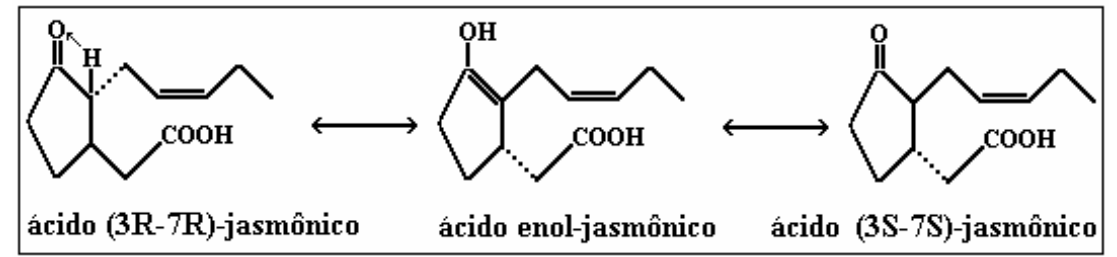

FIGURA 20 - ISÔMEROS CIS E TRANS DO ÁCIDO JASMÔNICO

\section{BIOSSÍNTESE DO ÁCIDO JASMÔNICO}

De acordo com Mueller (1997), a descoberta de que extratos de plantas eram capazes de sintetizar o ácido cis-12-oxo-fitodienóico quando incubados com os ácidos linoleico ou á-linolênico foi de fundamental importância para a elucidação das diversas etapas do metabolismo biossintético do ácido jasmônico.

Inicialmente, o ácido linoleico e principalmente o á-linolênico, constituintes dos acilglicerois e fosfolipídios das membranas plasmáticas das células vegetais são hidrolisados por lipases ou fosfolipases como resposta a diversos estímulos externos, a exemplo da cicatrização ou de ataque por patógenos. A Figura 21 resume a ação das lipases sobre as membranas plasmáticas das células vegetais. 


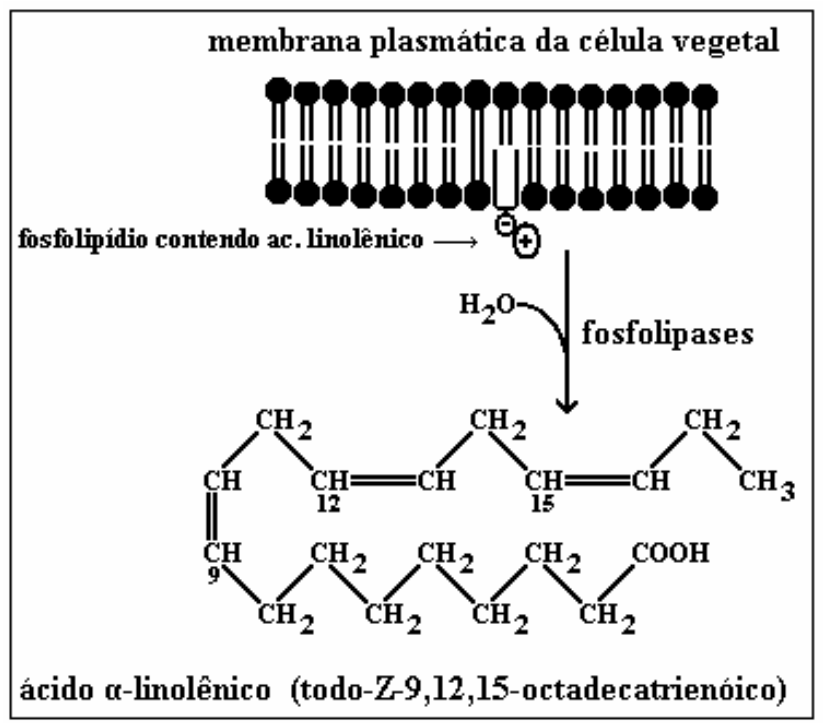

\section{FIGURA 21 - HIDRÓLISE DE LIPÍDIOS MEMBRANÁCEOS PELAS LIPASES}

Livres no citoplasma, os ácido graxos são ativados por aciltiocinases de média especificidade para derivados acil-CoA (LI et al., 2005). A Figura 21 resume essas etapas.

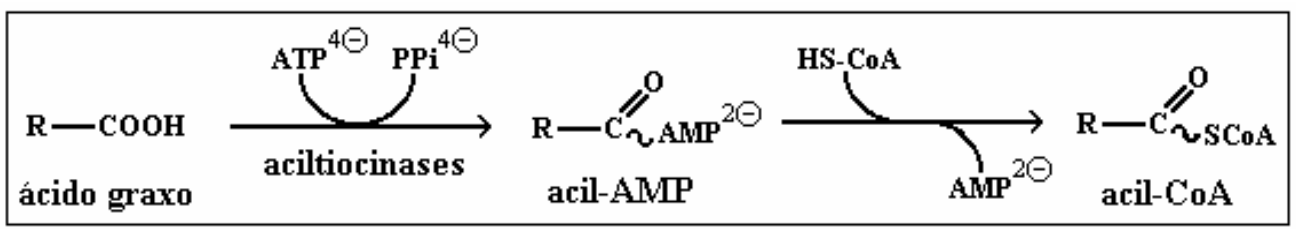

\section{FIGURA 22 - RESUMO DA ATIVAÇÃO DOS ÁCIDOS GRAXOS}

A ligação aciltiólica, rica em energia, garante as combinações de acilas ativadas com outros metabólitos como na formação de diversos ésteres em reações enzimaticamente controladas por acilCoA transferases mais ou menos específicas. Os ácidos livres facilmente reagiriam com cátions diversos, a exemplo daqueles divalentes como o cálcio com a formação de sabões não desejados. Provavelmente, a maioria dos ácidos graxos obtidos como metabólitos intermediários nessa biossíntese está na forma de acil-CoA.

Apesar da literatura especializada não se referir aos derivados acil-CoA, esses serão considerados quando ajudarem no entendimento. Ainda de acordo com Mueller (1997), os mais importantes fornecedores de ácido á-linolênico nos cloroplastos das plantas superiores são os galactolipídios, digalactosil-diacilglicerois presentes em seus complexos membranáceos.

A primeira etapa da transformação do ácido á-linolênico em ácido jasmônico é catalisada por uma lipoxigenase (linoleato: oxigênio oxidorredutase) diferente daquela que nos animais inicia a biossíntese dos prostanoides e é específica para os ácidos araquidônico e eicosapentenoico (EPA). Nas plantas, ela tem os ácidos linoleico e á-linolênico como os substratos mais utilizados (GRECHKIN, 1998). Ela catalisa a oxigenação do ácido á-linolênico formando o ácido 13(S)hidroperóxi-9(Z)-11(E)-15(Z)-octadecatrienoico ou ácido 13(S)-11(E)-hidroperóxi-linolênico, como apresentado na Figura 23. 


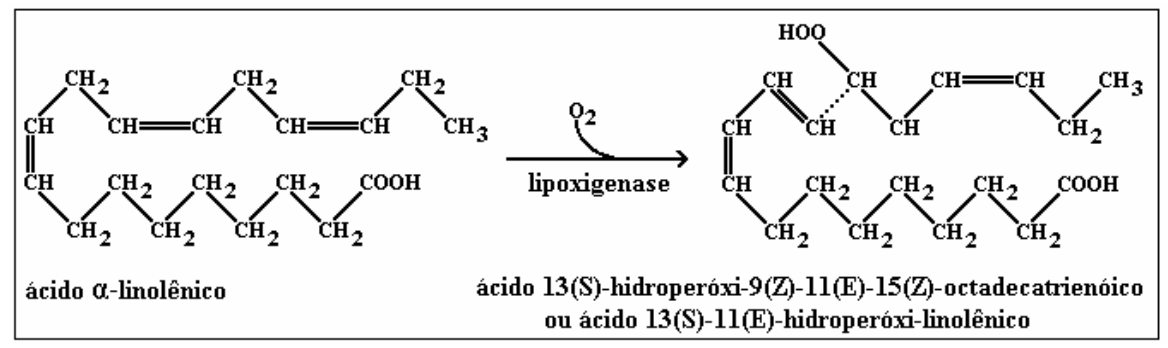

\section{FIGURA 23 - AÇÃO DA LIPOXIGENASE SOBRE O ÁCIDO á-LINOLÊNICO}

As lipoxigenases são dioxigenases que apresentam ferro não hemínico em seus centros ativos e que catalisam, estereoespecificamente, a oxigenação de sistemas pentadiênicos 1-(Z)-4-(Z) formando 1-hidroperóxi-2-(E)-(Z)-pentadienos. São amplamente difundidas nos reinos vegetal e animal, incluindo fungos, leveduras e algas (MUELLER, 1997).

A atividade das lipoxigenases nas plantas pode ser fortemente alterada pelo $\mathrm{pH}$ ácido do meio reacional. A forma dissociada do ácido á-linolênico é muito pouco reconhecida pelo seu centro ativo. Essa é mais uma observação a favor de que os ácidos graxos não permanecem, na maioria dos casos, livres e dissociados nos diversos compartimentos celulares, mas sim ligados a grupos de transportes como a coenzima $A$.

O ácido 13(S)-11(E)-hidroperóxi-linolênico é muito instável e imediatamente protegido pelo centro ativo da aleno-óxido sintetase (hidroperóxido deidrase) que o transforma no derivado epóxi, o ácido 12,13(S)-epóxi-9(Z)-11(E)-15(Z)-octadecatrienoico, conforme mostra a Figura 24.

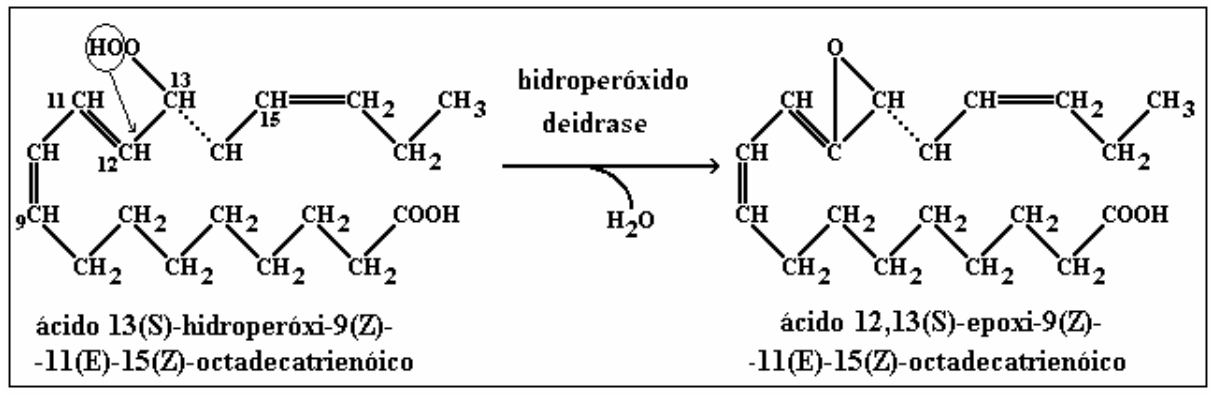

\section{FIGURA 24 - TRANSFORMAÇÃO DO DERIVADO HIDROPERÓXIDO DO ÁCIDO 9(Z)-11(E)-15(E)-OCTADECATRIENOICO NO EPÓXI CORRESPONDENTE}

A aleno óxido sintetase é uma hemoproteína de $55 \mathrm{kDa}$ (quilo daltons) com espectro semelhante ao citocromo $\mathrm{P} 450$, e número de renovação de $1000 \mathrm{~min}^{-1}$. É uma das mais abundantes enzimas ligadas ao metabolismo dos hidroperóxidos de ácidos graxos nas plantas. Isolada de diferentes fontes vegetais é capaz de metabolizar vários hidroperóxidos de ácidos graxos, contudo, é bem mais ativa e específica para aqueles que apresentam um grupo peróxido nos carbonos ù-6,7 e uma dupla ligação na configuração $Z$, no carbono ù-3. Os óxidos de alenos são muito instáveis quando em solução aquosa e apresentam meia vida química de aproximadamente 20 segundos. Logo são hidrolisados para os cetois correspondentes (MUELLER, 1997).

O derivado epóxi do ácido á-linolênico é instável e imediatamente transformado pela aleno óxido ciclase em ácido 12-oxo-10,15(Z)-fitodienoico (12-oxo-PDA). A Figura 25 mostra essa ciclização. 


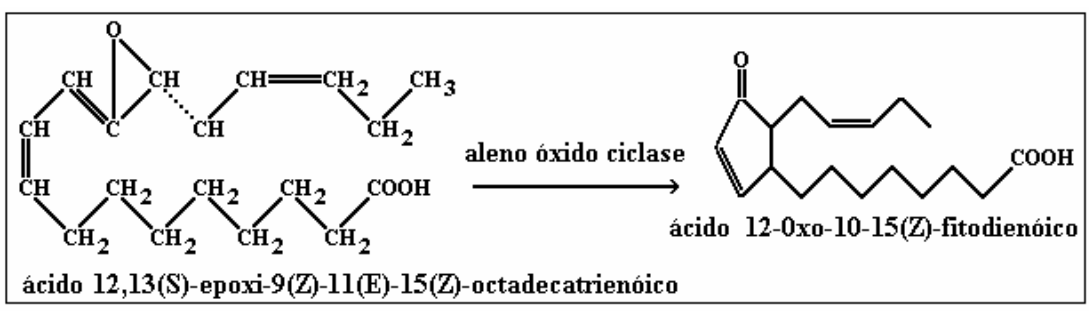

FIGURA 25 - AÇÃO DA ALENO ÓXIDO CICLASE

A 12-oxo-PDA redutase catalisa a redução da dupla ligação entre os carbonos 10 e 11 formando 0 núcleo ciclopentenona do ácido 10,11-diidro-12-oxo-15(Z)-fitodienóico, conforme apresentado na Figura 26. Essa redutase de aproximadamente $54 \mathrm{kDa}$, isolada das sementes e plântulas do milho (Zea mays), apresenta ampla faixa de pH entre 6.8 e 9.0 para sua atividade ótima e é dependente de NADP reduzido. In vitro pode-se utilizar o NAD (nicotinamida adenina dinucleotídio) reduzido como agente redutor, contudo, numa concentração 323 vezes maior.

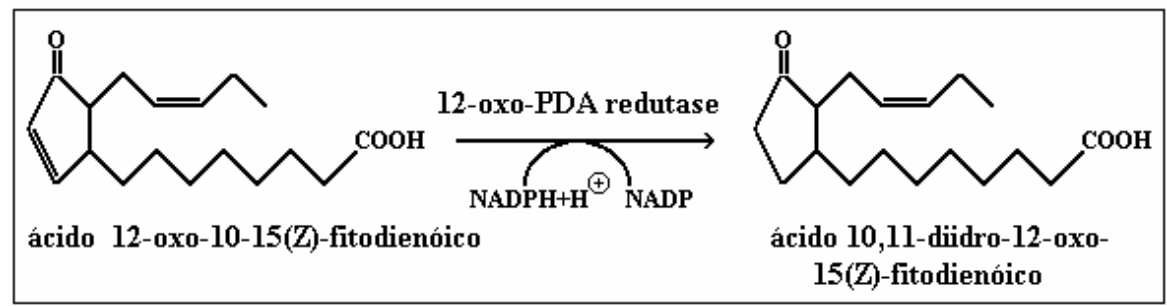

FIGURA 26 - REDUÇÃO DO ÁCIDO 12-OXO-10-15(Z)-FITODIENÓICO

A transformação do ácido 10,11-diidro-12-oxo-fitodienóico em ácido jasmônico envolve a retirada de seis átomos de carbonos da cadeia lateral saturada, provavelmente depois de submetê-lo 3 vezes sucessivas à â-oxidação. Segundo Masterson e Wood (2001), esse metabolismo ocorre em dois compartimentos celulares nas plantas superiores: os peroxissomos e as mitocôndrias. A Figura 27 mostra que ambos requerem a ativação do acila graxo e a ação da acil-CoA: carnitina aciltransferase para o seu transporte entre os compartimentos envolvidos.

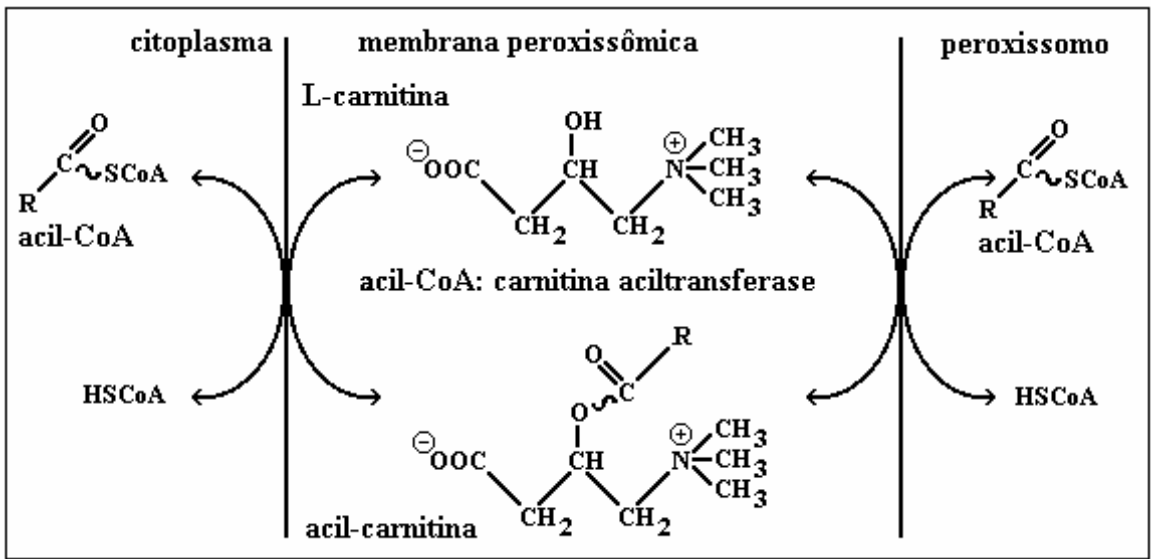


Os acilas graxos ativados pela CoA são bioquimicamente compartimentalizados e não passam livremente de um compartimento celular a outro. No caso de troca entre o citoplasma, os peroxissomos, os plastídios e as mitocôndrias, os acilas ligados à CoA são transportados com velocidades diferentes na dependência do grupo acila. Nos animais, o palmitil-CoA é aquele melhor transportado entre os compartimentos mitocondrial e citoplasmático. Parte da energia gasta nesse transporte vem do gradiente de concentração do próprio acila ativado nos dois compartimentos envolvidos.

Li et al. (2005) descreveram que a biossíntese do jasmonato ocorre, principalmente, em dois compartimentos celulares. Da utilização do ácido á-linolênico até a formação do ácido 12oxo-fitodienoico, essas transformações se passam nos plastídios. Aquelas que levam à formação do ácido jasmônico, inclusive as referentes à â-oxidação da cadeia lateral, ocorrem nos peroxissomos. Nesses orgânulos, a â-oxidação de acilas graxos ativados pela CoA é catalisada pelo conjunto de três enzimas que constituem uma estrutura proteica pentenária chamada de acil-CoA oxidase. Essa enzima multifuncional contêm a 2-trans-enoil-CoA hidratase, a L-3hidroxiacil-CoA desidrogenase e a 3-cetoacil-CoA tiolase. Enquanto as duas primeiras enzimas estão envolvidas na â-oxidação propriamente dita, a última libera o cis-jasmonil-CoA. Finalmente, a tioesterase presente nos plastídios hidrolisa a ligação tioéster do cis-jasmonil-CoA, liberando-o para o citoplasma conforme resume a Figura 28 (KUNZE et al., 2006).

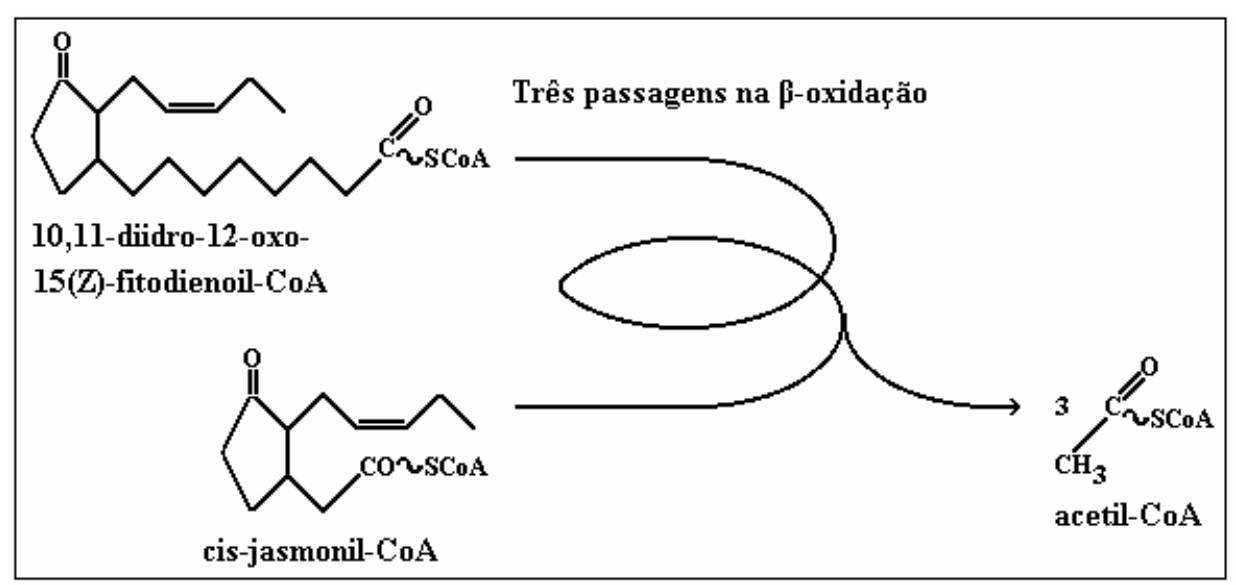

\section{FIGURA 28 - ESQUEMA RESUMIDO DA â-OXIDAÇÃO DO 10,11-DIIDRO-12-OXO-15(Z)- FITODIENOIL-COA}

Como se trata de ácido de fraca dissociação, o cis-jasmônico pode ser acumulado nos cloroplastos e outros compartimentos celulares. Ele pode atuar como segundo mensageiro na indução de efeitos os mais diversos, a exemplo da inibição do crescimento das raízes quando encontram obstáculo mecânico ou outras perturbações físicas, como o vento ou o contato prolongado que induzem mudanças no crescimento da planta. O jasmonato se acumula nas células dos tecidos lesados por ação dos herbívoros, estando envolvido nos mecanismos de cicatrização e recuperação dos tecidos das plantas. Ele e o seu éster metílico inibem o crescimento de sementes não dormentes e estimulam a germinação daquelas dormentes. Aparentemente, derivados voláteis do ácido jasmônico estão envolvidos na atração de insetos relacionados com a polinização das flores. Além disso, o ácido jasmônico participa da floração, frutificação e amadurecimento do fruto (WASTERNACK, 2007). Sua ligação com os mecanismos de defesa das plantas aos agentes exógenos como os insetos está relacionada à sua transformação em jasmolona, uma das retrolonas componentes das piretrinas I e II. Nesse sentido, a oxidação do núcleo da ciclopentenona entre os carbonos 3 e 7 do ácido jasmônico induz a sua descarboxilação formando a jasmona (cis) como metabólito intermediário. A Figura 29 resume a formação da cis-jasmona. 


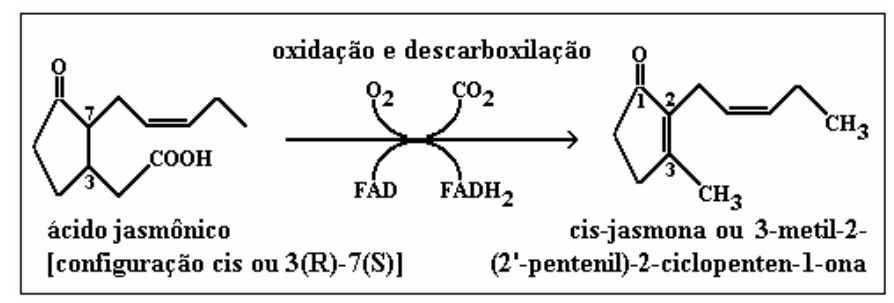

FIGURA 29 - OXIDAÇÃO E DESCARBOXILAÇÃO DO ÁCIDO CIS-JASMÔNICO

Provavelmente, a oxidorredutase envolvida na oxidação é FAD (flavina adenina dinucleotídio) dependente e forma peróxido de hidrogênio como um dos produtos. $O$ ataque do peróxido de hidrogênio no grupo carbonila/carboxílica do ácido cis-jasmônico induz a descarboxilação e à formação da cis-jasmona.

A última etapa de biossíntese da jasmolona tem duas vertentes de acordo com Matsuda et al. (2005). Uma mais direta e que consiste na hidroxilação do carbono 4 da cis-jasmona pela enzima 4áhidroxilase dependente de oxigênio molecular e NADP reduzido como mostrado na Figura 30.

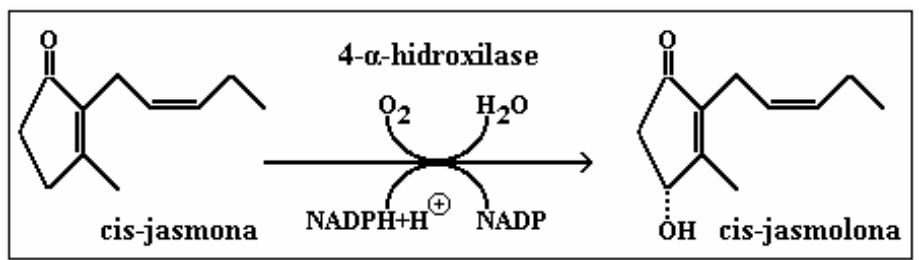

FIGURA 30 - HIDROXILAÇÃO DA CIS-JASMONA

$\mathrm{Na}$ alternativa que não passa pela cis-jasmona, a 4á-hidroxilase oxida o carbono 4 do ácido cis-jasmônico formando o metabólito intermediário, ácido 4á-hidroxi-cis-jasmônico, o qual depois de ser oxidado nos carbonos 3 e 7 do ciclopentano é descarboxilado para cis-jasmolona. Essas reações são mostradas na Figura 31.

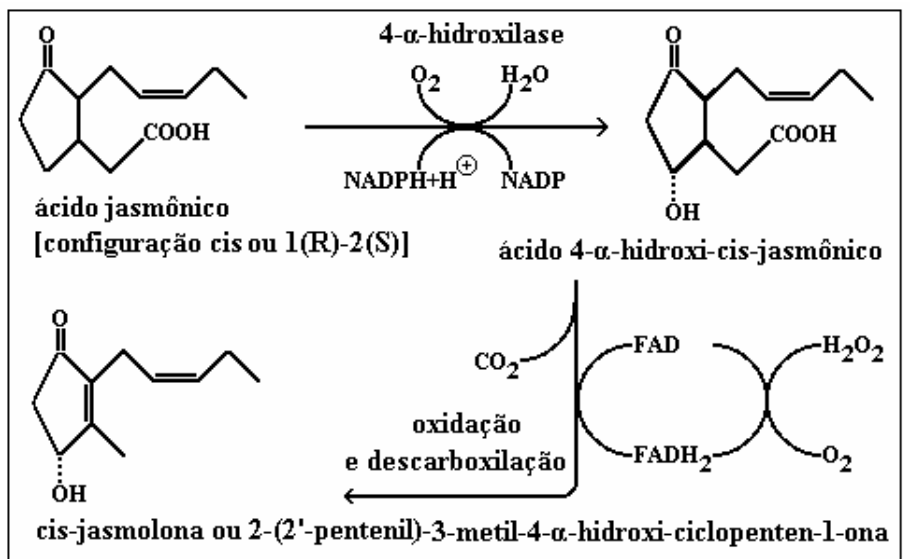

\section{FIGURA 31 - ALTERNATIVA DA BIOSSÍNTESE DA CIS-JASMOLONA}

\section{BIOSSÍNTESE DAS PIRETRINAS I E II}

Como foi salientado, as piretrinas naturais constituintes do píretro são ésteres dos ácidos crisantêmico e do pirétrico, com as retrolonas (piretrolona, jasmolona e cinerolona). O ácido pirétrico mostrado na Figura 32, é derivado do ácido crisantêmico como éster metílico do carbono 3 da cadeia metilpropenílica. 
<smiles>COC(=O)C=C1C(C(=O)O)C1(C)C</smiles>

ácido pirétrico ou ácido 3(3-metoxi-2-metil-3-oxo1-propenil)-2,2-dimetil ciclopropano carboxilico

\section{FIGURA 32 - ESTRUTURA ESPACIAL SIMPLIFICADA DO ÁCIDO PIRÉTRICO}

Provavelmente, os ácido crisantêmico e pirétrico são ativados pela CoA antes de reagirem com as retrolonas para a formação das ligações estéricas que caracterizam as piretrinas dos tipos I e II. Essa ativação pela CoA parece necessária para o fornecimento da energia utilizada na formação do éster em pauta. A Figura 33 resume a formação da piretrina II.

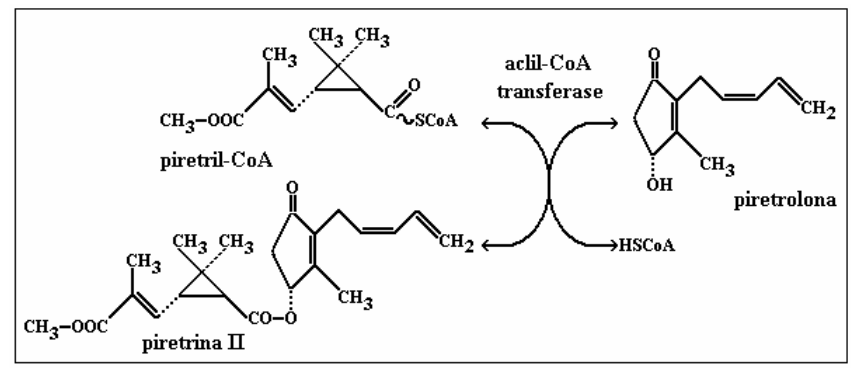

FIGURA 33 - FORMAÇÃO DA PIRETRINA II PELA ACIL-COA TRANSFERASE

\section{CONSIDERAÇÕES FINAIS}

Esta revisão sobre o metabolismo biossintético das piretrinas I e ll em que as etapas mais importantes foram consideradas teve a intenção de contribuir para maior compreensão dessas vias metabólicas e facilitar o desenvolvimento das pesquisas, assim como a obtenção industrial desses importantes inseticidas.

\section{ABSTRACT \\ CONSIDERATIONS ABOUT PYRETHRINS' I AND II BIOSYNTHETIC METHABOLISM - LITERATURE REVIEW AND SUGESTIONS}

This review on the biosynthetic metabolic pathways of pyrethrins I and II, includes several intermediary stages of these metabolic processes, in order to facilitate an understanding of the numerous biochemical barriers that remain to be clarified. Despite of the substantial industrial development in the manufacture of pyrethrins' synthetic derivatives such as pyrethroids, its high demand and commercial importance continue to stimulate the biosynthesis of these insecticides through biotechnology, the use of bioreactors, the bioconversion of precursors by isolated enzymes of leaves and flowers of the chrysanthemum or through genetically modified microorganisms.

KEY-WORDS: PYRETHROIDS; INSECTICIDES; CHRYSANTHEMIC ACID; ISOPRENOIDS.

\section{REFERÊNCIAS}

1 ALEX, D.; BACH, T.J.; CHYE, M.L. Expression of Brassica juncea 3-hydroxy-3-methylglutaryl CoA synthase is developmentally regulated and stress-responsive. The Plant Journal, v.22, n.5, p.415-426, 2000.

2 BOUVIER, F.; RAHIER, A.; CAMARA, B. Biogenesis, molecular regulation and function of plant isoprenoids. Progress in Lipid Research, v.44, p.357-429, 2005. 
3 CHAPPELL, J.; WOLF, F.; PROULX, J.; CUELLAR, R.; SAUNDERS, C. Is the reaction catalyzed by 3-hydroxy-3methylglutaryl coenzyme A reductase a rate-limiting step for isoprenoid biosynthesis in plants? Plant Physiology, v.109, p.1337-1343, 1995.

4 D'AURIA, J.C. Acyltransferases in plants: a good time to be BAHD. Current Opinion in Plant Biology, v.9, p.331$340,2006$.

5 EISENREICH, W.; SCHWARZ, M.; CARTAYRADE, A.; ARIGONI, D.; ZENK, M.H.; BACHER, A. The deoxyxylulose phosphate pathway of terpenoid biosynthesis in plant and microorganisms. Chemistry \& Biology, v.5, n.9, p.221-233, 1998.

6 ERICKSON, H.K.; POULTER, C.D. Chrysanthemyl diphosphate synthase. The relationship among chain elongation, branching and cyclopropanation reactions in the isoprenoid biosynthetic pathway. American Journal of Chemical Society, v.125, p.6886-6888, 2003.

7 GLYNNE-JONES, A. Pyrethrum. Pesticide Outlook, v.12, p.195-198, 2001.

8 GRECHKIN, A. Recent developments in biochemistry of plant lipoxygenase pathway. Progress in Lipid Research, v.37, n.5, p.317-352, 1998.

9 JOVETIC, S. Natural pyrethrins and biotechnological alternatives. Biotechnology and Development Monitor, v.21, p.12-13, 1994.

10 KIM, S-M.; KUZUYAMA, T.; KOBAYASHI, A.; SANDO, T.; CHANG, Y-J.; KIM, S-U. 1-hydroxy-2-methyl-2-(E)-butenyl-4diphosphate reductase (IDS) is encoded by multicopy genes in gymnosperms Ginkgo biloba and Pinus taeda. Planta, v.227, p.287-298, 2008.

11 KUNZE, M.; PRACHAROENWATTANA, I.; SMITH, S.M.; HARTIG, A. A central role of the peroxisomal membrane in glyoxylate cycle function. Biochimica et Biophysica Acta, v.1763, p.1441-1452, 2006.

12 LI, C.; SCHILMILLER, A.L.; LIU, G.; LEE, G.I.; JAYANTY, S.; SAGEMAN, C.; VREBALOV, J.; GIOVANNONI, J.J.; YAGI, K.; KOBAYASHI, Y.; HOWE, G.A. Role of â-oxidation in jasmonate biosynthesis and systemic wound signaling in tomato. The Plant Cell, v.17, p.971-986, 2005.

13 LICHTENTHALER, H.K. The 1-deoxy-D-xylulose-5-phosphate pathway of isoprenoid biosynthesis in plants. Annual Review of Plant Physiology and Plant Molecular Biology, v.50, p.47-65, 1999.

14 MCCASKILL, D.; CROTEAU, R. Isopentenyl diphosphate is the terminal product for deoxyxylulose-5-phosphate pathway of terpenoid biosynthesis in plants. Tetrahedron Letters, v.40, p.653-655, 1999.

15 MASTERSON, C.; WOOD, C. Mitochondrial and peroxisomal â-oxidation capacities of organs from a non-oilseed plant. Proceedings of Royal Society of London B, v.268, p.1949-1953, 2001.

16 MATSUDA, K.; KIKUTA, Y.; HABA, A.; NAKAYAMA, K.; KATSUDA, Y.; HATANAKA, A.; KOMAI, K. Biosynthesis of pyrethrin I in seedlings of Chrysanthemum cinerariaefolium. Phytochemistry, v.66, p.1529-1535, 2005.

17 MISSINOU, M.A.; BORRMANN, S.; SCHINDLER, A.; ISSIFOU. S.; ADEGNIKA. A.A.; MATSIEGUI, P.B.; BINDER, R.; LELL, B.; WIESNER, J.; BARANEK, T.; JOMAA, H.; KREMSNER, P.G. Fosmidomycin for malaria. The Lancet, v.360, p.19411942, 2002.

18 MUELLER, M.J. Enzymes involved in jasmonic acid biosynthesis. Physiologia Plantarum, v.100, p.653-663, 1997.

19 REUTER, K.; SANDERBRAND, S.; JOMAA, H.; WEISNER, J.; STEINBRECHER, I.; BECK, E.; HINTZ, M.; KLEBE, G.; STUBBS, M.T. Crystal structure of 1-deoxy-D-xylulose-5-phosphate reductoisomerase, a crucial enzyme in the nonmevalonate pathway of isoprenoid biosynthesis. The Journal of Biological Chemistry, v.277, n.7, p.5378-5384, 2002.

20 RODRIGUES, L.E.A. Lipídios: aspectos bioquímicos e médicos. Salvador: EDUFBA, 2006. 280 p.

21 ROHMER, M.; KNANI, M.; SIMONIN, P.; SUTTER, B.; SAHM, H. Isoprenoid biosynthesis in bacteria: a novel pathway for the early steps leading to isopentenyl diphosphate. The Biochemical Journal, v.295, p.517-524, 1993.

22 STERMER, B.A.; BIANCHINI, G,M.; KORTH, K.L. Regulation of HMG-CoA reductase activity in plants. Journal of Lipid Research, v.35, p.1133-1140, 1994.

23 WANYIKA, H.N.; KARERU, P.G.; KERIKO, J.M.; GACHANJA, A.N.; KENJI, G.M.; MUKIIRA, N.J. Contact toxicity of some fixed plant oils and stabilized natural pyrethrum extracts against adult maize weevils (Sitophilus zeamais Motschulsky). African Journal of Pharmacy and Pharmacology, v.3, n.2, p.66-69, 2009.

24 WASTERNACK, C. Jasmonates: an update on biosynthesis, signal transduction and action in plant stress response, growth and development. Annals of Botany, v.100, n.4, p.681-697, 2007.

25 WITHERS, S.T.; KEASLING, J.D. Biosynthesis and engineering of isoprenoid small molecules. Applied Microbiology and Biotechnology, v.73, p.980-990, 2007. 